\title{
What kind of support do teachers really need in a blended learning context?
}

\author{
Shurong Zhao, Junxia Song \\ School of Foreign Languages, Shandong Women's University, China
}

\begin{abstract}
Teachers in higher education are the principal participants in blended learning (BL). Without their engagement, any attempt at BL might fail. In the process of BL implementation, they are faced with various challenges and are mostly not well prepared. However, studies have often neglected the feeling of teachers and their anxieties during BL implementation. There is insufficient research on teacher-related factors, especially teacher support. To address this question, a questionnaire was conducted among 123 respondents from 10 universities in China between March and May 2020. An analysis of the data collected shows that BL is widely recognised by teachers, but they lack confidence in their competence in BL implementation. The top three difficulties that faculty face are increased workload, a lack of funds to build their own courses and a lack of time to prepare online activities. Further, respondents have a clear need for pedagogical support, financial and infrastructure support, policy support, technical support and emotional support. These findings indicate that a targeted support system should be constructed to address these difficulties. Special attention should be paid to formulating BL guidance, offering a supportive environment that values BL efforts and relieving the workload of faculty.
\end{abstract}

Implications for practice or policy:

BL teachers need various support to design and implement BL courses.

- Higher education institutions should formulate guidance and clarify the definition and key implementation elements to guide BL practice.

- Management departments of higher education institutions should take effective measures to alleviate the burden of teachers.

- The training of teachers in the application of BL technology should focus on strengthening technological content knowledge and technological pedagogical knowledge.

Keywords: blended learning (BL), difficulties, need analysis, teacher support, technological pedagogical content knowledge (TPACK)

\section{Introduction}

The rapid development of technology is transforming the world. Blended learning (BL), as a systematic integration of technology application and face-to-face instruction, has become a focus of research and practice in higher education. As Garrison and Vaughan (2008) pointed out, when BL is fully understood and applied, higher education will experience the most dramatic evolution since the expansion in the 1940s. During the COVID-19 pandemic, most classes have been transferred online, with various technological tools exploited to aid learning and instruction. Teachers have gradually accepted and become used to the mode of technology-integrated instruction, suggesting that BL will be used more widely and become routine in higher education in the post-pandemic period (Wong, 2020).

Teachers are the principal participants in the delivery of BL, being the designers, implementers, administrators and decision-makers of these courses. Without the engagement of teachers, any attempt at BL might fail (Christo-Baker, 2004; Graham \& Robison, 2007). Studies have thoroughly proven the benefits and effectiveness of BL (Graham, 2006; Osguthorpe \& Graham, 2003; Zawilinski et al., 2016), but often neglected the feelings of teachers, the challenges they meet, their difficulties, anxieties and worries before and during the implementation of BL.

To adopt the new paradigm of integrating online and offline instruction, teachers face dramatic role changes. Coppola et al. (2002) conducted a semi-structured interview study and identified three new roles of teachers in online instruction: the cognitive role, emotional role and administrative role. For the cognitive 
role, instruction turns to deeper cognitive complexity; in the emotional aspect, teachers are required to give more emotional expression, even though they have known their students well; and from an administrative perspective, teachers are expected to care more about details, offer structured instruction and carry out more supervision of learners' learning behaviour. Easton (2003) found two new roles of teachers in online instruction: instruction designer and interaction facilitator. Facing these challenges brought about by the integration of technology into learning, teachers have to adapt to these new roles and inevitably face various difficulties.

BL means not only a change in the roles of teachers but also higher requirements. They are required to master the necessary teaching techniques and apply them flexibly according to different online and offline objectives. Garrison and Kanuka (2004) pointed out that the real test of BL lies in the effective combination of the two components (face-to-face and online learning) and that no two BL designs are identical. This reflects the high complexity of BL and its great challenge for designers and implementers. BL calls for a high degree of engagement, a spirit of innovation and cooperation from teachers. The design of BL involves expertise in various fields. Therefore, collaboration is essential when a measurable aim is to be achieved. In the knowledge dimension, BL teachers should have content knowledge, technological knowledge, pedagogical knowledge and course management knowledge (Edmondson \& Nembhard, 2009). McGee and Reis (2012) found that teachers face three dilemmas in designing BL, namely understanding which learning activities are suitable for online sessions and which are appropriate for face-to-face delivery, how to balance the relationship between face-to-face and online sessions and how to allocate face-to-face and online learning time. All these challenges and questions constitute practical barriers to the successful implementation of BL and lead to faculty feeling anxious and frustrated (Feng et al., 2018; Porter et al., 2016).

Teachers usually hold contradictory attitudes towards BL. Bliuc et al. (2012) found five categories of perceptions of BL from faculty: cultivating life-long learning, matching the needs of learners and helping them achieve their objectives, improving access to resources, highlighting the function of face-to-face sections and leading to the more effective use of it and involving the appropriate application of educational technology. Feng et al. (2018) held that the more experienced BL implementers are, the more contradictory attitudes they hold. They recognise the effects of BL and its strengths in facilitating knowledge acquisition and self-regulatory strategies. On the contrary, they are troubled by the extra workload, the challenges of restructuring course design and a lack of confidence in technology application and even sometimes feel frustrated (Philipsen et al., 2019). The efficient use of BL depends to a large extent on the competence and readiness of teachers, but the fact is that many of them are not yet well prepared.

To address the challenges brought about by BL, it is necessary to provide teachers with appropriate support and build a teacher support system (Albó \& Hernández-Leo, 2020). Weber et al. (2019) probed the support for pre-service and novice teachers, pointing out that their self-efficacy is significantly related to the support they want and that adequate support can protect their self-efficacy. Hockly (2018) concluded that teacher training is an important aspect of teacher support. Cuesta Medina (2018) pointed out that successful BL involves well-designed plans, theoretically supported instructional models, high-quality teacher development, curriculum development assistance, learner support systems and ongoing formative and summative evaluations. Among them, curriculum development assistance is an important element of teacher support. Porter et al. (2014) analysed the factors that affect teachers' adoption of BL from another perspective: adequate infrastructure, technical support, pedagogical support, evaluation and institutions' implementation of BL objectives. Antwi-Boampong (2020) concluded that to promote the adoption of BL among teachers, four core elements need to be considered. First, higher education institutions must evaluate their own readiness, including policy frameworks and implementation strategies. Second, faculty should have technical familiarity and technical acceptance. Third, institutions should provide teachers with a complete support system. Fourth, institutions should provide hardware infrastructure for BL. All these findings prove the necessity of teacher support in BL contexts and offer hints about the elements of a support system. Hence, this study, based on findings of studies, aimed to address the following research questions (RQs):

- RQ1. What are teachers' perceptions of BL and of their own BL practice?

- RQ2. What are the difficulties and problems encountered by teachers in their implementation of BL?

- RQ3. What kind of support do teachers need in a BL context? 


\section{Theoretical background}

\section{Teacher support}

Graham et al. (2013) divided the application of institutional-level BL into three stages, namely awareness and exploration, adoption and implementation and maturity and growth. They argued that teacher support comprises technical support, pedagogical support and incentives. This offers hints about the meaning of teacher support. Furthermore, support also means enabling teachers to spend time on their ideas and providing them with appropriate training and knowledge so that they can implement and evaluate their work (Kotter, 2009). With appropriate support, teachers who design a new BL model can receive feedback. Higher education institutions show publicly that they value this behaviour and are ready to help with curriculum development. Poon (2013) pointed out that institutions should provide support in several dimensions, including information technology, continuous investment, support by senior administrators and teacher training. Porter et al. (2014) summarised the supporting framework that educational institutions should provide for BL, which consists of three dimensions and 10 sub-dimensions. The three dimensions are strategy, structure and support; and the 10 sub-dimensions are purpose, advocacy, definition, infrastructure, scheduling, governance, evaluation, professional development, support and incentives. This provides a theoretical framework and strategic guidance for top-level design and support of BL reform at the institutional level. Agostinho et al. (2018) conducted a qualitative study that investigated the types of support that 30 teachers reported that they used in their design work. These were colleagues, literature, workshops and seminars, conferences, institutional support services and enrolment in postgraduate study.

The community of inquiry framework (Garrison et al., 1999) is a recognised and widely used online learning model (Anderson, 2008; Feng et al., 2018). It regards the online learning experience as a result of the interaction of three presences: social, cognitive and teaching. Social and cognitive presence refers to the engagement of students and their interaction with the content. Teaching presence is the central element and it focuses on teachers' engagement. The three presences should be taken into consideration when investigating the need for teacher support in the context of BL and constructing a support framework.

\section{Technological pedagogical content and knowledge (TPACK) framework}

In a BL context, information technology plays an important role. For teachers' information technology application ability, Mishra and Koehler (2006) proposed the TPACK framework, which consists of three knowledge domains: content knowledge (CK), pedagogical knowledge (PK) and technological knowledge (TK). These three domains are often integrated and intertwined in teaching. Their interaction forms four subfields: technological content knowledge (TCK), technological pedagogical knowledge (TPK), pedagogical content knowledge (PCK) and TPACK. Among them, TPACK can be defined as the knowledge that teachers combine with specific technology and with appropriate pedagogical methods when teaching specific materials or knowledge. The TPACK framework is widely used in the field of educational technology research to evaluate the appropriateness of technology in teaching, to select the technology to promote teaching, to select the technology of learning evaluation and to serve as reference for applying technology in the classroom of various disciplines. Mulyadi et al. (2020) used the TPACK framework and explored the specific application of TCK, TPK, PCK and TPACK in the field of English for Specific Purposes. One of their conclusions is that technology can be used to teach aspects such as listening, reading, vocabulary and oral English, but is rarely used in teaching grammar. In the BL context, TPACK has become an important means for measuring faculty competence. The definition and application of the TPACK framework provide a basis and realistic reference for the questionnaire design of this study, thereby laying a foundation for investigating the actual situation of teachers' educational technology abilities and the obstacles they face.

\section{Research methodology}

To address the three research questions, we conducted a questionnaire between March and May 2020 to explore the status of teachers' BL adoption, the main difficulties they face and the kind of support they need to prepare for and implement BL. 


\section{Context of the study}

China's BL implementation features the active advocacy of the government. The Ministry of Education of the People's Republic of China (MOE) has promoted the use of online learning management systems and development of online course resources (Han et al., 2016). It advocates that universities should deeply integrate information technology with education to achieve educational innovation and has launched related policies to encourage BL adoption. In the Double Ten Thousand Plan for the certification of first-class undergraduate courses, the MOE (2019) plans to build about 10,000 national and 10,000 provincial-level first-class (high-quality) undergraduate courses in about 3 years, of which BL courses account for the largest proportion (37.5\%). BL courses based on high-quality online courses are especially favoured in this plan. Under the advocacy of the MOE, colleges and universities actively build online resources or introduce them for use in BL. Attempts of BL in other countries have involved the use of teacher-developed resources such as worked example videos or screencasts with low production requirements but with satisfactory effects (Ahmad et al., 2013; Dart et al., 2020), or those sourced from various social media outlets. However, the MOE has imposed strict technical standards and a high level of quality requirements for online courses, including those regarding video resolution, embedded subtitles and tests. Therefore, it is nearly impossible for teachers to develop online resources themselves for use in BL. They are compelled to resort to and cooperate with specialised commercial institutions, which involves high costs.

The advocacy of the government and higher education institutions has become one of the main driving forces for the adoption of BL in China. Han et al. (2019) conducted a questionnaire on BL implementation in China and found a top-down mode in all the six institutions investigated and that the implementation of $\mathrm{BL}$ is highly related to online courses. The development or import of online courses has therefore become one of the prerequisites for the implementation of BL in China.

\section{Questionnaire design and analysis}

We designed the online questionnaire based on the theory of BL implementation and support and teacher development. It was checked by two external experts. As the mother language of all the participants is Chinese, in order to avoid inaccurate answers due to language barrier, we wrote the questionnaire in Chinese. When stating the research findings, we translated the items into English. To list the factors of difficulty and measures of support in the questionnaire, we referred to the questionnaire of Mulyadi et al. (2020), support sub-dimensions of Poon (2013) and support measures of Porter et al. (2014). In addition to basic information, the questionnaire included two multiple-choice questions, three open-ended questions and 57 statements for indicating a level of agreement or disagreement using a 5-point Likert scale $(1=$ strongly disagree, $2=$ disagree, $3=$ not sure, $4=$ agree and $5=$ strongly agree). A pilot study of the questionnaire was administered before the formal questionnaire. Five teachers from our university (4 with previous BL implementation experience and 1 with no such experience) voluntarily participated the pilot study. They filled in the questionnaire and commented on the items in terms of difficulty and desirable support measures for BL, offering suggestions for new items or deleting redundant ones. Changes and amendments were made accordingly. After the pilot and deletion of items with low reliability, the Cronbach's $\alpha$ of the final questionnaire was 0.853 and that of each dimension was above 0.8 , which indicates a high degree of internal consistency and reliability.

The items of the questionnaire centred on the three research questions. Regarding RQ1, multiple-choice questions and statements were used to inquire whether respondents had implemented BL and the reasons as well as their confidence in BL implementation. Regarding RQ2, the items about the difficulties faced by teachers fell into five dimensions: workload, financial matters and policies, students (student-related difficulties), technology (technical difficulties faced by teachers and students) and competency (teaching, design competencies and TPACK). Regarding RQ3, items on teachers' need for support measures were in five dimensions: pedagogical support, policy support, infrastructure and financial support, technical support and emotional support. To avoid inaccurate answers due to a vague understanding of the key concept, the questionnaire included Garrison and Kanuka's (2004) definition of BL - the thoughtful integration of faceto-face interaction and online learning - in three prominent positions.

The results of the questionnaire were analysed with SPSS version 17.0. Descriptive analysis was used to explore the status and rank the difficulties and supportive measures in order of importance. Independent $t$ tests and one-way ANOVAs were used to find the factor differences. 


\section{Participants}

The questionnaire was conducted in 2020 among teachers in higher education institutions in Shandong Province, China. A snowball sampling method was adopted. First, eight teachers from eight universities were invited to answer the questionnaire, and then they were asked to invite other teachers to also participate. The data were collected in strict accordance with the rules and guidelines applicable to ethical research practices involving human participants. Teachers were invited to participate regardless of whether they carried out BL. The questionnaire set skipping item selections for teachers who had not adopted BL, inquiring about their reasons for this. A total of 123 valid questionnaires were collected, and the teachers participating were from 10 universities in Shandong Province, 66 of whom had implemented BL in their teaching. All the respondents were teaching undergraduate students. Altogether, 29 of them are from science disciplines, including mathematics, physics, computer science and technology, while 84 are from social science disciplines, including foreign languages, education, sociology, management and economics. The demographic information of the respondents is presented in Table 1. It shows that the questionnaire covered a wide range of respondents, representing teachers of various ages, teaching experience and BL adoption experience.

Table 1

Demographic information of the participants $(N=123)$

\begin{tabular}{|c|c|c|c|c|c|}
\hline \multirow[t]{2}{*}{ Characteristic } & \multirow[t]{2}{*}{ No. $(\%)$} & \multicolumn{2}{|c|}{ Female } & \multicolumn{2}{|c|}{ Male } \\
\hline & & No. & Percentage & No. & Percentage \\
\hline \multicolumn{6}{|l|}{ Gender } \\
\hline & $123(100 \%)$ & 106 & $86.18 \%$ & 17 & $13.82 \%$ \\
\hline \multicolumn{6}{|l|}{ Age } \\
\hline $21-30$ & $16(13.01 \%)$ & 12 & $9.76 \%$ & 4 & $3.25 \%$ \\
\hline $31-35$ & $28(22.76 \%)$ & 25 & $20.32 \%$ & 3 & $2.43 \%$ \\
\hline $36-40$ & $51(41.46 \%)$ & 46 & $37.39 \%$ & 5 & $4.06 \%$ \\
\hline $41-45$ & $20(16.26 \%)$ & 17 & $13.82 \%$ & 3 & $2.43 \%$ \\
\hline $46-50$ & $5(4.07 \%)$ & 3 & $2.43 \%$ & 2 & $1.62 \%$ \\
\hline $51-55$ & $2(1.62 \%)$ & 2 & $1.62 \%$ & 0 & 0 \\
\hline $56-60$ & $1(0.81 \%)$ & 1 & $0.81 \%$ & 0 & 0 \\
\hline $61-65$ & 0 & 0 & 0 & 0 & 0 \\
\hline \multicolumn{6}{|c|}{ Years of teaching at university } \\
\hline $1-5$ & $27(21.95 \%)$ & 22 & $17.88 \%$ & 5 & $4.06 \%$ \\
\hline $6-10$ & $26(21.14 \%)$ & 24 & $19.51 \%$ & 2 & $1.62 \%$ \\
\hline $11-15$ & $38(30.89 \%)$ & 34 & $27.64 \%$ & 4 & $3.25 \%$ \\
\hline $16-20$ & $23(18.7 \%)$ & 20 & $16.26 \%$ & 3 & $2.43 \%$ \\
\hline $21-25$ & $6(4.88 \%)$ & 4 & $3.25 \%$ & 2 & $1.62 \%$ \\
\hline $26-30$ & $3(2.44 \%)$ & 2 & $1.62 \%$ & 1 & $0.82 \%$ \\
\hline More than 30 & 0 & 0 & 0 & 0 & 0 \\
\hline \multicolumn{6}{|c|}{ Years of adopting BL } \\
\hline 0 & $57(46.34 \%)$ & 50 & $40.65 \%$ & 7 & $5.69 \%$ \\
\hline $1-3$ & $61(49.59 \%)$ & 53 & $43.08 \%$ & 8 & $6.50 \%$ \\
\hline $4-6$ & $3(2.44 \%)$ & 2 & $1.62 \%$ & 1 & $0.81 \%$ \\
\hline $7-9$ & $2(1.62 \%)$ & 1 & $0.81 \%$ & 1 & $0.81 \%$ \\
\hline More than 9 & 0 & 0 & 0 & 0 & 0 \\
\hline
\end{tabular}

\section{Findings}

\section{Current status of teachers' adoption of BL}

Regarding BL adoption (Table 2), 66 out of the 123 respondents had already implemented BL, accounting for $53.66 \%$. A total of 48 respondents were not using BL, but they planned to adopt it. After these two figures are added together, $92.68 \%$ of respondents had already adopted BL or planned to implement it. Only one respondent had neither carried out nor planned to adopt BL. This leads to the tentative conclusion that the majority of teachers recognise and accept the BL mode and that it will become dominant in higher education in the near future. 
Table 2

BL adoption

\begin{tabular}{|c|c|c|}
\hline Item & $N$ & Percentage \\
\hline I have adopted BL. & 66 & $53.66 \%$ \\
\hline I have not adopted BL but plan to adopt it in the future. & 48 & $39.02 \%$ \\
\hline I have not adopted BL and have no plan to adopt it in the future. & 1 & $0.81 \%$ \\
\hline I have not adopted BL and I am not sure whether I will adopt it in the future. & 8 & $6.50 \%$ \\
\hline Total & 123 & $100 \%$ \\
\hline
\end{tabular}

Among the respondents who had adopted BL, 61 had been teaching for 1-3 years, accounting for 92.4\%. Only five respondents reported a relatively long implementation time. This shows that the current development of BL is still in its early stage and few teachers have mature experience.

There were three items in the questionnaire about self-evaluation of competence in implementing BL. The mean value of the item "I sometimes feel confused in implementing BL" was 3.47 and that of the item "I meet difficulties in implementing BL" was 3.453. The item "I can completely manage the implementation of BL" had a mean value of 2.491. These data indicate that respondents were not confident in their ability to use BL effectively.

An independent $t$ test was used to compare the self-evaluation of respondents of different sexes on BL implementation competence, and a one-way ANOVA was used to compare the self-evaluation of teachers across age groups. The results show a significant difference in the former (see Table 3, $\mathrm{p}<0.05$ ); female respondents were significantly less confident than male respondents. Age, teaching experience and BL experience varied for men compared with women in the sample (as shown in Table 1). In the latter, the self-evaluation of respondents across age groups did not show a significant difference.

Table 3

Gender difference in self-evaluation of BL competence

\begin{tabular}{lcccc}
\hline Item & \multicolumn{2}{c}{ Gender (Mean \pm Std deviation) } & $t$ & $p$ \\
& Male $(n=10)$ & Female $(n=56)$ & & \\
\hline I sometimes feel confused in implementing BL. & $2.50 \pm 1.18$ & $3.46 \pm 0.99$ & -2.755 & $0.008^{* *}$ \\
I meet difficulties in implementing BL. & $2.60 \pm 1.17$ & $3.54 \pm 0.96$ & -2.458 & $0.017^{*}$ \\
\hline
\end{tabular}

$* p<0.05 * * p<0.01$

Regarding the reasons for adopting BL, the item was a multiple-choice question, the result of which is shown in Table 4. The most frequently selected reason was "For better teaching effect", accounting for $74.24 \%$, which indicates that respondents recognise the positive effect of BL. The reason ranking second in frequency was "I like trying new technology", accounting for $37.88 \%$, followed by "It is a task assigned by schools/colleges", accounting for $36.36 \%$. The majority of respondents were young and middle-aged teachers; they like trying new things, especially new technology. Out of the 24 respondents in the 23-35 age group who adopted BL, 17 stated that they did so because they liked the process of trying out new technology. This also shows that the advocacy of institutions has become an important motivating factor for teachers to adopt BL. Since 2019, under the vigorous advocacy of the MOE (2019), universities have encouraged teachers to carry out BL reforms and offered a number of BL funding projects. Therefore, most of the efforts of BL feature a top-down model, as also found by Han et al. (2019). This is different from the widespread bottom-up approaches in other countries (Graham et al., 2013; Wang et al., 2015).

Table 4

Reasons for adopting BL

\begin{tabular}{lll}
\hline Item & $N$ & Percentage \\
\hline For better teaching effect. & 49 & $74.24 \%$ \\
For applying for projects. & 6 & $9.09 \%$ \\
Because there are incentives. & 5 & $7.58 \%$ \\
There is an example of successful implementation. & 13 & $19.7 \%$ \\
Because I like trying new technology. & 25 & $37.88 \%$ \\
It is a task assigned by schools/colleges. & 24 & $36.36 \%$ \\
Other & 3 & $4.55 \%$ \\
\hline
\end{tabular}


Altogether, 57 respondents reported not having carried out BL and were asked about the reasons. There were 13 statements about reasons, ranked on a 5-point Likert scale. As shown in Table 5, the reasons are sorted in descending order of the mean value. The reason "I plan to adopt, but I am not well-prepared at present" has the highest mean value (3.591), indicating that they intend to adopt BL but are limited by conditions. The reason ranking second is "I worry about too much time devotion". Devoting too much time is an important reason why respondents did not adopt BL. This is consistent with the findings of studies on obstacles to BL (Alammary et al., 2014; Crawford \& Jenkins, 2017). The reason ranking third is "I worry about poor participation of students", followed by "There are no appropriate online resources". Students are the main participants in BL, and their engagement and satisfaction are important factors in measuring the effectiveness of BL. Teachers' worries about poor participation have become a negative factor in their BL adoption (O’Flaherty \& Phillips, 2015).

Table 5

Reasons for not implementing $B L(N=57)$

\begin{tabular}{lllll}
\hline Item & Min & Mean (1-5) & Max & Std deviation \\
\hline I plan to adopt, but I am not well-prepared at present. & 2 & 3.591 & 5 & 0.889 \\
I worry about too much time devotion. & 1 & 3.368 & 5 & 1.159 \\
I worry about poor participation of students. & 1 & 3.018 & 5 & 1.203 \\
There are no appropriate online resources. & 1 & 3.000 & 5 & 1.052 \\
There is no incentive policy. & 1 & 2.965 & 5 & 0.981 \\
I know little about BL, and there is no example to follow. & 1 & 2.947 & 5 & 1.025 \\
Wait and see. I will adopt BL after others do. & 1 & 2.877 & 5 & 1.087 \\
I think that BL will lead to lower learning achievement. & 1 & 2.737 & 5 & 1.009 \\
BL is not suitable for my course. & 1 & 2.579 & 5 & 0.963 \\
I am not competent in adopting technology in teaching. & 1 & 2.579 & 5 & 1.133 \\
I do not want to change my current mode of teaching. & 1 & 2.246 & 5 & 1.023 \\
\hline
\end{tabular}

\section{Teachers' difficulties in BL implementation}

Identifying the main difficulties and obstacles faced by teachers in BL and proposing targeting measures and suggestions were the key goals of this study. When designing this part of the questionnaire, we consulted previous studies on BL obstacles and collected the elements of difficulty from respondents who participated in the pilot.

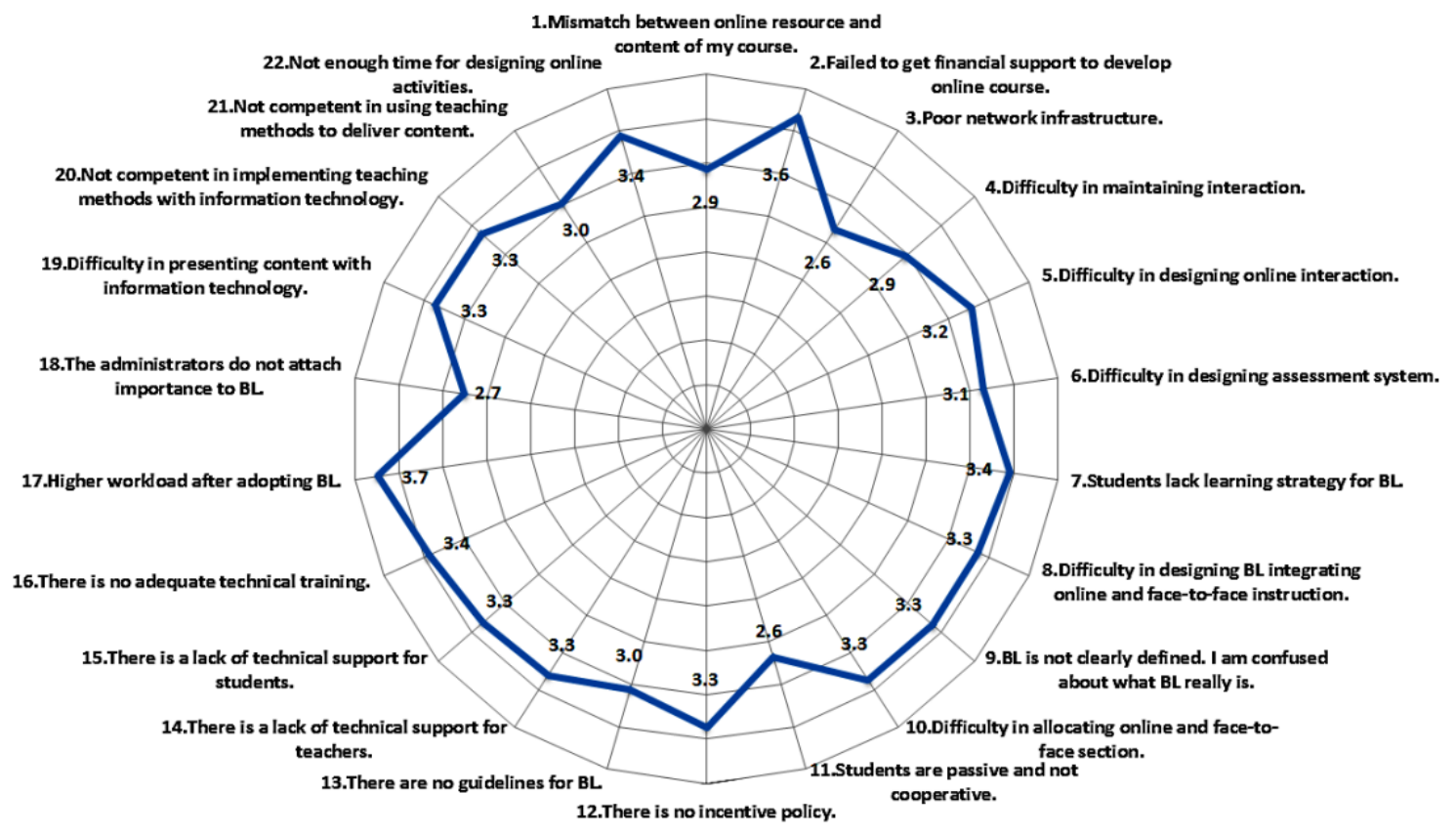

Figure 1. Difficulties teachers encountered in implementing BL 
For this part of the questionnaire, respondents were the 66 teachers who had already implemented BL. The questionnaire has 22 items on a 5-point Likert scale. The items about the difficulties faced by teachers fall into five dimensions: workload, financial matters and policies, students, technology and competency. The overall descriptive statistics for the 22 items are illustrated in Figure 1, showing the high and low mean values of the items. In Table 6, the items are arranged in descending order of the mean value, and only items with mean values higher than 3 are listed. The top five difficulties teachers met are increased workload, failure to obtain financial support to develop their online courses, a lack of new technology training, a lack of time to prepare online activities and confusion caused by vague definitions of BL.

Table 6

Difficulties in BL implementation $(N=66)$

\begin{tabular}{|c|c|c|c|c|}
\hline Item & Min & Max & $\begin{array}{l}\text { Mean } \\
(1-5)\end{array}$ & Std deviation \\
\hline 17. Higher workload after adopting BL. & 1 & 5 & 3.742 & 1.012 \\
\hline $\begin{array}{l}\text { 2. I want to develop my own online course but failed to } \\
\text { obtain financial support. }\end{array}$ & 1 & 5 & 3.667 & 1.1 \\
\hline 7. The students lack a learning strategy for BL. & 1 & 5 & 3.455 & 1.01 \\
\hline 16. There is no adequate technical training. & 1 & 5 & 3.439 & 1.025 \\
\hline $\begin{array}{l}\text { 22. I do not have enough time to prepare for designing } \\
\text { online activities. }\end{array}$ & 1 & 5 & 3.439 & 1.01 \\
\hline $\begin{array}{l}\text { 9. BL is not clearly defined. I am confused about what } \\
\text { BL really is. }\end{array}$ & 1 & 5 & 3.379 & 0.957 \\
\hline $\begin{array}{l}\text { 19. I lack the ability to present teaching content with } \\
\text { information technology. }\end{array}$ & 1 & 5 & 3.374 & 1.062 \\
\hline $\begin{array}{l}\text { 8. It is difficult for me to design BL that integrates } \\
\text { online and face-to-face instruction. }\end{array}$ & 1 & 5 & 3.364 & 0.905 \\
\hline $\begin{array}{l}\text { 10. It is difficult to allocate appropriate portions for } \\
\text { online and face-to-face sections. }\end{array}$ & 1 & 5 & 3.364 & 0.971 \\
\hline $\begin{array}{l}\text { 11. Students are passive and not cooperative, which } \\
\text { leads to poor learning. }\end{array}$ & 1 & 5 & 3.364 & 1.017 \\
\hline 12. There is no incentive policy in our university. & 1 & 5 & 3.364 & 1.017 \\
\hline $\begin{array}{l}\text { 20. I lack the ability to implement a certain teaching } \\
\text { method with information technology. }\end{array}$ & 1 & 5 & 3.364 & 1.104 \\
\hline 15. There is a lack of technical support for students. & 1 & 5 & 3.333 & 1.1 \\
\hline 14. There is a lack of technical support for teachers. & 1 & 5 & 3.303 & 1.189 \\
\hline 5. It is difficult to design online interaction. & 1 & 5 & 3.288 & 1.078 \\
\hline 6. It is difficult to design an assessment system. & 1 & 5 & 3.152 & 1.085 \\
\hline 13. There are no guidelines for BL in our university. & 1 & 5 & 3.061 & 1.149 \\
\hline $\begin{array}{l}\text { 21. I lack the ability to use appropriate teaching } \\
\text { methods to deliver the content. }\end{array}$ & 1 & 5 & 3.001 & 1.116 \\
\hline
\end{tabular}

The TPACK-related difficulties are shown in Table 7. The first item in the table is about TCK, the second is about TPK and the third is about PCK. The table shows that the mean values of TCK and TPK difficulties are significantly higher (3.374 and 3.364) than that of PCK difficulties (3.001), indicating that teachers have difficulties in technology-related competences rather than with the traditional methods (without technical assistance) to deliver content.

Table 7

TPACK-related difficulties $(N=66)$

\begin{tabular}{lcccc}
\hline Item & Min & Max & Mean (1-5) & Std deviation \\
\hline $\begin{array}{l}\text { I lack the ability to present teaching content with } \\
\text { information technology. }\end{array}$ & 1 & 5 & 3.374 & 1.062 \\
$\begin{array}{l}\text { I lack the ability to implement a certain teaching } \\
\text { method with information technology. }\end{array}$ & 1 & 5 & 3.364 & 1.104 \\
$\begin{array}{l}\text { I lack the ability to use appropriate teaching methods } \\
\text { to deliver the teaching content. }\end{array}$ & 1 & 5 & 3.001 & 1.116 \\
\hline
\end{tabular}




\section{Support measures needed by teachers}

There are 16 items in the questionnaire regarding teachers' need for support, divided into five dimensions. namely pedagogical support, financial and infrastructure support, policy support, technical support and emotional support (Table 8). The descriptive analysis of the questionnaire data is shown in Table 8, listing the 16 items in descending order of the mean value. The mean values of all 16 items exceed 4, indicating that teachers have a need for all those supporting factors. Among the 16 items, the one with the highest mean score is "I hope my efforts can be recognised and supported by students". Teachers value the cooperation and active participation of their main collaborators, students, especially in online activities. The type of need for support that ranks second in mean value is "I hope administrators can carry out measures to reduce our workload". Reducing a high workload has become an urgent need for teachers in BL implementation. The item that ranks third is "Obtaining funds to develop my own online course", followed by "Obtaining more opportunities to exchange experience of BL with other teachers", "I hope my efforts can be recognised and understood by administrators" and "I hope my efforts can be recognised and understood by peer teachers". The mean score of the item "BL experience sharing by experienced teachers", which ranks last, is 4.136 , indicating that this is also a type of support teachers want.

Table 8

Support measures needed by teachers $(N=66)$

\begin{tabular}{|c|c|c|c|c|c|}
\hline $\mathrm{D}$ & Item & Min & Max & Mean $(1-5)$ & SD \\
\hline \multirow[t]{3}{*}{ ES } & $\begin{array}{l}\text { I hope my efforts can be recognised and understood by } \\
\text { students. }\end{array}$ & 1 & 5 & 4.5 & 0.685 \\
\hline & $\begin{array}{l}\text { I hope my efforts can be recognised and understood by } \\
\text { administrators. }\end{array}$ & 1 & 5 & 4.409 & 0.744 \\
\hline & $\begin{array}{l}\text { I hope my efforts can be recognised and understood by peer } \\
\text { teachers. }\end{array}$ & 1 & 5 & 4.409 & 0.723 \\
\hline \multirow[t]{3}{*}{ PS } & $\begin{array}{l}\text { I hope administrators can carry out measures to reduce our } \\
\text { workload. }\end{array}$ & 1 & 5 & 4.455 & 0.727 \\
\hline & $\begin{array}{l}\text { Guidelines for BL issued by the teaching management } \\
\text { institution. }\end{array}$ & 1 & 5 & 4.394 & 0.721 \\
\hline & Incentive policy for BL. & 1 & 5 & 4.394 & 0.762 \\
\hline \multirow[t]{2}{*}{ FIS } & Obtaining funds to develop my own online course. & 1 & 5 & 4.455 & 0.706 \\
\hline & Better network conditions. & 1 & 5 & 4.318 & 0.826 \\
\hline \multirow[t]{2}{*}{ TS } & Training on educational technology. & 1 & 5 & 4.318 & 0.826 \\
\hline & Better technical assistance & 1 & 5 & 4.288 & 0.725 \\
\hline \multirow[t]{6}{*}{ PGS } & $\begin{array}{l}\text { Obtaining more opportunities to exchange experience of BL } \\
\text { with other teachers. }\end{array}$ & 1 & 5 & 4.409 & 0.841 \\
\hline & Training on BL design. & 1 & 5 & 4.303 & 0.822 \\
\hline & Training on BL pedagogy. & 1 & 5 & 4.288 & 0.818 \\
\hline & Lectures on BL by experts in this field. & 1 & 5 & 4.227 & 0.837 \\
\hline & Setting up cross-discipline BL communities. & 1 & 5 & 4.197 & 0.898 \\
\hline & BL experience sharing by experienced teachers. & 1 & 5 & 4.136 & 0.839 \\
\hline
\end{tabular}

Note. D: dimension; SD: standard deviation; ES: emotional support; PS: policy support; FIS: financial and infrastructure support; PGS: pedagogical support; TS: technical support.

The policy support dimension consists of three items, namely incentive policies, policies to reduce the burden of teaching and guidance documents on BL - all of which had high mean values. Among them, the mean value of policy needs to reduce the workload is 4.455 . Hence, measures by institutions to reduce teachers' workload are urgently needed.

The dimension of pedagogical support consists of six items about peer support and training support. The former covers peer experience sharing, peer exchange and the establishment of an interdisciplinary community. Among these three, more peer exchange opportunities had the highest mean value. The latter includes listening to expert lectures on BL and obtaining training in BL pedagogy and instructional design. The mean values of these three items are relatively high, and the one with the highest mean value is to obtain BL design training (4.303).

The dimension of financial and infrastructure support includes better network and financial support for developing their own online resources, and the mean value of the latter is significantly higher. There is an urgent need for many teachers to obtain funds to develop online. The emotional support dimension of the 
questionnaire consists of three items: the hope that their efforts will be recognised by the institution, the recognition of peers and the recognition and cooperation of students. For teachers, BL means a great challenge, a variety of problems and more time and energy. Therefore, they hope that their efforts will be recognised and supported emotionally so that they can move forward in their efforts to explore more effective BL.

\section{Discussion and implications}

The results of the questionnaire show that the vast majority of teachers recognise the positive role of BL. The top three reasons for teachers' adoption of BL are as follows: they recognise the effects of BL, they like trying new technologies, and BL adoption is a task assigned by the institution. This shows that teachers are no longer afraid of technology but are willing to use technology to improve teaching. This may also be because young and middle-aged teachers account for the majority of this sample. In addition, the advocacy of institutions has also become an important reason for the implementation of BL.

The results of the questionnaire also show that teachers are not confident in their competency to implement BL. They think that they lack the ability of interaction and assessment design and worry about poor cooperation of students. According to the community of inquiry framework, BL is the interaction of social presence, cognitive presence and teaching presence (Garrison et al., 1999). The perceptions of respondents and their worries cover all three presences, especially teaching presence. Competency support may include providing challenges, feedback, encouragement, guidance and assistance during task execution as well as offering clear expectations and guidelines. Specifically, competency support can also cover assistance to meet curriculum development needs and time management; the most effective support systems for teaching faculty are those that provide a development team for the development of BL courses (Garrison \& Kanuka, 2004). In BL, in addition to traditional roles, teachers also assume multiple roles such as providing online guidance, questions and answers, BL management and personalised guidance and assistance. It is difficult for teachers to cope with so many challenges. One way to solve this is to help build an interdisciplinary team. Such a team may include not only teachers of certain courses but also technicians and teachers specialising in pedagogy to develop a design model that suits the needs of specific disciplines.

The difficulties encountered by teachers in the implementation of BL in this study lie in several aspects, two of which deserve special attention. The first is the high workload, which has a high mean value. In addition, among teachers' support needs, the mean value of lightening the burden is very high. Orsini-Jones et al. (2017) found that the reasons for teachers failing to carry out BL after BL training included course restrictions, slow servers, online resources that do not meet learning needs and worry about increasing workload. Hence, the heavy burden of teachers is an urgent problem to be addressed in BL. Higher education institutions should take effective measures to alleviate it, for instance, by reducing classroom time and offering various kinds of teaching assistance.

One of the main concerns of this research is the support that teachers need in BL preparation and implementation. Regarding technical support, offering the right technical conditions is a prerequisite for BL. Before implementing BL, an institution should evaluate its technical readiness (Gautreau, 2016). A sound technical environment is needed, including convenient and fast campus network access and the embedding of learning management systems. The results of the questionnaire indicate that teachers need more technological support. Within the framework of TPACK (Mishra \& Koehler, 2006), it is TCK and TPK that teachers find difficult. Orsini-Jones et al. (2017) also showed that most teachers have experienced the integration of technology and teaching activities, but some have difficulty in assessing the suitability of the technology in teaching. In this situation, the training of teachers in the application of BL technology should focus on strengthening TCK and TPK, facilitating teachers' ability to use technology to realise their own teaching design, thereby achieving the teaching objectives effectively.

The support in the tripartite BL adoption model of higher education institutions proposed by Graham et al. (2013) comprises technical support, pedagogical support and incentives. In addition to these three aspects, our study found that financial and infrastructural support, policy support and emotional support are also important elements. In particular, teachers hope to receive funds to build their own online courses. In China, the implementation of $\mathrm{BL}$ is closely related to the development or import of online courses. The construction of an online course requires cooperation with commercial institutions (Wang et al., 2019), and 
this involves high costs. Therefore, in addition to the present projects favouring BL adoption, special funds should be set aside to aid teachers in their building or introduction of online courses.

Another kind of support often overlooked is emotional support. The results of the questionnaire show that emotional support is an essential part of the support teachers need. A drowsy, unmotivated student cohort will cause the teacher to lose motivation, making them teach in an uninspired and uninspiring way (Ellis, 2012). The results also show that teachers hope that their efforts will be recognised by the institution, peer teachers and students. Cleveland-Innes and Campbell (2012) added emotional presence to the key elements of the community of inquiry framework, namely teaching presence, social presence and cognitive presence (Garrison et al., 1999). Teacher emotion greatly affects BL implementation and their professional development. Aiming to meet teachers' emotional support needs, the institutional culture should emphasise BL experiments, support reform measures, and try to create a cooperative atmosphere for all teachers. Providing teachers with emotional support also involves creating a positive macro-environment, which is a key factor in BL success (Edmondson \& Nembhard, 2009). Only when teachers can clarify the meaning of $\mathrm{BL}$ and regard it as their obligation can BL become a new organisational routine. This macroenvironment should give teachers the right to innovate and apply BL and encourage the use of practicebased research to create and disseminate BL practices suitable for the institution.

\section{Limitations}

The limitations of the current study should be acknowledged. First, only 123 teachers participated, 66 of whom had BL implementation experience. Such a limited sample size may not represent the whole picture well; thus, future studies should be conducted on a greater number of teachers and from even broader disciplines. Furthermore, because female teachers usually account for the majority of faculty, especially in social science disciplines, there were only 17 male respondents in the study, which influences, to some extent, the comparison result of BL competence across sexes. The third limitation lies in our reliance upon descriptive analysis to analyse the data collected, using only independent $t$ tests and one-way ANOVAs to find the factor differences.

\section{Conclusion}

Teachers face a variety of challenges in the implementation of BL. To probe the difficulties and explore related countermeasures, this study conducted a needs analysis of teacher support, addressing three research questions, namely the current status of BL implementation, the difficulties and problems encountered by teachers in the BL context and their need for support. The findings offer insights into teachers' need for support in the typical top-down context of BL adoption and provide practical implications for designing a customised teacher support system. Furthermore, they can serve as a reference point for future teaching and research.

The data analysis shows that BL is widely accepted and will become the dominant mode of course delivery in higher education in China. One of the important driving forces lies in the advocacy of the government and institutions. The analysis of the self-evaluation items shows that teachers are not confident in their ability to conduct BL. The independent $t$ tests show that female respondents have significantly lower selfconfidence in their BL ability than male respondents. The self-definition of respondents across age groups does not show significant differences.

The data analysis on the difficulties faced by teachers in BL shows that the item with the highest mean value is about increased workload, followed by a lack of financial support to develop their own online courses. What ranks third is the lack of training on applying new technology. This indicates that these factors are the most prominent difficulties faced by teachers in BL implementation. The data analysis also shows that the problem of workload is a common difficulty faced by teachers and needs to be solved urgently. Among the items of the teaching competence dimension, the difficulty in teaching design has the highest mean score.

Regarding teachers' need for support in the BL context, all 16 items for support measures had high mean values. Among them, the highest is "I hope my efforts can be recognised and understood by students", followed by "I hope my efforts can be recognised and understood by administrators". What ranks third is 
"I hope administrators can carry out measures to reduce our workload", followed by "Obtaining funds to develop my own online course" and "Obtaining more opportunities to exchange experience of BL with other teachers". In the dimension of teaching support, more peer exchange opportunities and BL design training are the most urgent. The data of the emotional support dimension shows that teachers are eager to obtain emotional recognition and support for their efforts.

Future research may use our findings as evidence to propose a support system that provides guidance and aid in BL implementation tailored to the needs of different groups of teachers in different modes of teaching. Overall, teachers are faced with challenges and need various types of support in a BL context. On the basis of knowing this, what specific utilities will these measures achieve? How can a targeted teacher support system be constructed in the top-down context of BL adoption? Further research could involve enquiries in these directions.

\section{References}

Agostinho, S., Lockyer, L., \& Bennett, S. (2018). Identifying the characteristics of support Australian university teachers use in their design work: Implications for the learning design field. Australasian Journal of Educational Technology, 34(2), 1-15. https://doi.org/10.14742/ajet.3776

Ahmad, T. B. T., Doheny, F., Faherty, S., \& Harding, N. (2013). How instructor-developed screencasts benefit college students' learning of maths: Insights from an Irish case study. The Malaysian Online Journal of Educational Technology, 1(4), 12-25. https://mojet.net/ParticleDetail?id=208

Alammary, A., Sheard, J., \& Carbone, A. (2014). Blended learning in higher education: Three different design approaches. Australasian Journal of Educational Technology, 30(4), 440-454. https://doi.org/10.14742/ajet.693

Albó, L., \& Hernández-Leo, D. (2020). Conceptualising a visual representation model for MOOC-based blended learning designs. Australasian Journal of Educational Technology, 36(4), 1-26. https://doi.org/10.14742/ajet.5178

Anderson, T. (Ed.). (2008). The theory and practice of online learning (2nd ed.). Athabasca University Press. https://www.aupress.ca/books/120146-the-theory-and-practice-of-online-learning/

Antwi-Boampong, A. (2020). Towards a faculty blended learning adoption model for higher education. Education and Information Technologies, 25(3), 1639-1662. https://doi.org/10.1007/s10639-01910019-Z

Bliuc, A. M., Casey, G., Bachfischer, A., Goodyear, P., \& Ellis, R. A. (2012). Blended learning in vocational education: Teachers' conceptions of blended learning and their approaches to teaching and design. The Australian Educational Researcher, 39(2), 237-257. https://doi.org/10.1007/s13384-012$\underline{0053-0}$

Christo-Baker, E. (2004). Distance education leadership in higher education institutions: Explored within theoretical frameworks of organizational change and diffusion of innovations theory. In L. Cantoni \& C. McLoughlin (Eds.), Proceedings of ED-MEDIA 2004: World Conference on Educational Multimedia, Hypermedia \& Telecommunications (pp. 251-256). Association for the Advancement of Computing in Education. https://www.learntechlib.org/p/12940/

Cleveland-Innes, M., \& Campbell, P. (2012). Emotional presence, learning, and the online learning environment. The International Review of Research in Open and Distributed Learning, 13(4), 269292. https://doi.org/10.19173/irrodl.v13i4.1234

Coppola, N. W., Hiltz, S. R., \& Rotter, N. G. (2002). Becoming a virtual professor: Pedagogical roles and asynchronous learning networks. Journal of Management Information Systems, 18(4), 169-189. https://doi.org/10.1080/07421222.2002.11045703

Crawford, R., \& Jenkins, L. (2017). Blended learning and team teaching: Adapting pedagogy in response to the changing digital tertiary environment. Australasian Journal of Educational Technology, 33(2), 51-72. https://doi.org/10.14742/ajet.2924

Cuesta Medina, L. (2018). Blended learning: Deficits and prospects in higher education. Australasian Journal of Educational Technology, 34(1), 42-56. https://doi.org/10.14742/ajet.3100

Dart, S., Pickering, E., \& Dawes, L. (2020). Worked example videos for blended learning in undergraduate engineering. Advances in Engineering Education, 8(2), 1-22. https://doi.org/10.18260/3-1-1153-36021

Easton, S. S. (2003). Clarifying the instructor's role in online distance learning. Communication Education, 52(2), 87-105. https:// doi.org/10.1080/03634520302470 
Edmondson, A. C., \& Nembhard, I. M. (2009). Product development and learning in project teams: The challenges are the benefits. Journal of Product Innovation Management, 26(2), 123-138. https://doi.org/10.1111/j.1540-5885.2009.00341.x

Ellis, R. (2012). Language teaching research and language pedagogy. John Wiley \& Sons. https://doi.org/10.1002/9781118271643

Feng, X., Wang, R., \& Wu, J. (2018). A literature review on blended learning: Based on analytical framework of blended learning. Distance Education, 36(3), 13-24. https://doi.org/10.15881/j.cnki.cn33-1304/g4.2018.03.002

Garrison, D. R., Anderson, T., \& Archer, W. (1999). Critical inquiry in a text-based environment: Computer conferencing in higher education. The Internet and Higher Education, 2(2-3), 87-105. https://doi.org/10.1016/S1096-7516(00)00016-6

Garrison, D. R., \& Kanuka, H. (2004). Blended learning: Uncovering its transformative potential in higher education. The Internet and Higher Education, 7(2), 95-105. https://doi.org/10.1016/j.iheduc.2004.02.001

Garrison, D. R., \& Vaughan, N. D. (2008). Blended learning in higher education: Framework, principles, and guidelines. Jossey-Bass. https://doi.org/10.5465/amle.7.1.31413871b

Gautreau, C. (2016). Motivational factors affecting the integration of a learning management system by faculty. The Journal of Educators Online, 8(1). https://doi.org/10.9743/JEO.2011.1.2

Graham, C. R. (2006). Blended learning systems: Definition, current trends, and future directions. In C. J. Bonk \& C. R. Graham (Eds.), Handbook of blended learning: Global perspectives, local designs (pp. 3-21). Pfeiffer Publishing.

Graham, C. R., \& Robison, R. (2007). Realizing the transformational potential of blended learning: Comparing cases of transforming blends and enhancing blends in higher education. In A. G. Picciano \& C. D. Dziuban (Eds.), Blended learning: Research perspectives (pp. 83-110). Sloan Consortium.

Graham, C. R., Woodfield, W., \& Harrison, J. B. (2013). A framework for institutional adoption and implementation of blended learning in higher education. The Internet and Higher Education, 18(3), 414. https://doi.org/10.1016/j.iheduc.2012.09.003

Han, X., Wang, Y., Li, B., \& Cheng, J. (2016). Case study of institutional implementation of blended learning in five universities of China. In C. P. Lim (Ed.), Blended learning for quality higher education: Selected case studies on implementation from Asia-Pacific (pp. 265-296). UNESCO Press. https://bangkok.unesco.org/content/blended-learning-quality-higher-education-selected-case-studiesimplementation-asia-pacific

Han, X., Wang, Y., \& Jiang, L. (2019). Towards a framework for an institution-wide quantitative assessment of teachers' online participation in blended learning implementation. The Internet and Higher Education, 42, 1-12. https://doi.org/10.1016/j.iheduc.2019.03.003

Hockly, N. (2018). Blended learning. ELT Journal, 72(1), 97-101. https://doi.org/10.1093/elt/ccx058

Kotter, J. (2009). Leading change: Why transformation efforts fail. IEEE Engineering Management Review, 37(3), 42-48. https://doi.org/10.1109/EMR.2009.5235501

McGee, P., \& Reis, A. (2012). Blended course design: A synthesis of best practices. Online Learning, 16(4), 7-22. https://doi.org/10.24059/olj.v16i4.239

Ministry of Education. (2019). 一流本科课程建设的实施意见 [Implementation opinions on construction of first-class undergraduate courses]. http://www.moe.gov.cn/srcsite/A08/s7056/201910/t20191031_406269.html

Mishra, P., \& Koehler, M. J. (2006). Technological pedagogical content knowledge: A framework for teacher knowledge. Teachers College Record, 108(6), 1017-1054. https://www.tcrecord.org/content.asp?contentid=12516

Mulyadi, D., Wijayatingsih, T. D., Budiastuti, R. E., Ifadah, M., \& Aimah, S. (2020). Technological pedagogical and content knowledge of ESP teachers in blended learning format. International Journal of Emerging Technologies in Learning, 15(6), 124-139. https://doi.org/10.3991/ijet.v15i06.11490

O'Flaherty, J., \& Phillips, C. (2015). The use of flipped classrooms in higher education: A scoping review. The Internet and Higher Education, 25, 85-95. https://doi.org/10.1016/j.iheduc.2015.02.002

Orsini-Jones, M., Zou, B., Hu, Y., \& Wei, L. (2017). Chinese English teachers' perspectives on "distributed flip MOOC blends": From BMELTT to BMELTE. International Journal of ComputerAssisted Language Learning and Teaching, 7(4), 1-14. https://doi.org/10.4018/IJCALLT.2017100101

Osguthorpe, R. T., \& Graham, C. R. (2003). Blended learning environments: Definitions and directions. Quarterly Review of Distance Education, 4(3), 227-233. https://www.infoagepub.com/qrdeissue.html?i=p54c69ed9966e3 
Philipsen, B., Tondeur, J., Pynoo, B., Vanslambrouck, S., \& Zhu, C. (2019). Examining lived experiences in a professional development program for online teaching: A hermeneutic phenomenological approach. Australasian Journal of Educational Technology, 35(5), 46-59. https://doi.org/10.14742/ajet.4469

Poon, J. (2013). Blended learning: An institutional approach for enhancing students' learning experiences. Journal of Online Learning and Teaching, 9(2), 271-288. https://jolt.merlot.org/vol9no2/poon 0613.htm

Porter, W. W., Graham, C. R., Bodily, R. G., \& Sandberg, D. S. (2016). A qualitative analysis of institutional drivers and barriers to blended learning adoption in higher education. The Internet and Higher Education, 28, 17-27. http://doi.org/10.1016/j.iheduc.2015.08.003

Porter, W. W., Graham, C. R., Spring, K. A., \& Welch, K. R. (2014). Blended learning in higher education: Institutional adoption and implementation. Computers \& Education, 75, 185-195. https://doi.org/10.1016/j.compedu.2014.02.011

Wang, X. H., Hall, A. H., \& Wang, Q. Y. (2019). Investigating the implementation of accredited massive online open courses (MOOCs) in higher education: The boon and the bane. Australasian Journal of Educational Technology, 35(3), 1-14. https://doi.org/10.14742/ajet.3896

Wang, Y., Han, X., \& Yang, J. (2015). Revisiting the blended learning literature: Using a complex adaptive systems framework. Educational Technology and Society, 18(2), 380-393. https://www.jstor.org/stable/jeductechsoci.18.2.380

Weber, K. E., Prilop, C. N., \& Kleinknecht, M. (2019). Effects of blended and video-based coaching approaches on preservice teachers' self-efficacy and perceived competence support. Learning, Culture and Social Interaction, 22, 119-141. https://doi.org/10.1016/j.lcsi.2019.100318

Wong, R. (2020). When no one can go to school: Does online learning meet students' basic learning needs? Interactive Learning Environments. https://doi.org/10.1080/10494820.2020.1789672

Zawilinski, L. M., Richard, K. A., \& Henry, L. A. (2016). Inverting instruction in literacy methods courses: Making learning more active and personalized. Journal of Adolescent and Adult Literacy, 59(6), 695-708. https://doi.org/10.1002/jaal.498

Corresponding author: Shurong Zhao, cathy@sdwu.edu.cn

Copyright: Articles published in the Australasian Journal of Educational Technology (AJET) are available under Creative Commons Attribution Non-Commercial No Derivatives Licence (CC BY-NC-ND 4.0). Authors retain copyright in their work and grant AJET right of first publication under CC BY-NC-ND 4.0 .

Please cite as: Zhao, S., \& Song, J. (2021). What kind of support do teachers really need in a blended learning context? Australasian Journal of Educational Technology, 37(4), 116-129. https://doi.org/10.14742/ajet.6592 